\title{
Nueva ruralidad y dinámicas de proximidad en el desarrollo territorial de los sistemas agroalimentarios localizados
}

\author{
Jonathan López-Santos \\ Universidad Nacional Autónoma de México, Ciudad de México, México. \\ Email: jonathan.ls@sociales.unam.mx \\ Tirzo Castañeda-Martínez \\ Centro Universitario UAEM, Universidad Autónoma del Estado de México, \\ Tenancingo, México \\ Email: tcastanedam@uaemex.mx \\ Justino Gerardo González-Díaz \\ Centro Universitario UAEM, Universidad Autónoma del Estado de México, \\ Tenancingo, México \\ Email: ocupa60@hotmail.com
}

\begin{abstract}
Resumen $^{1}$ : La nueva ruralidad como enfoque permite interpretar los procesos de desarrollo territorial de los Sistemas agroalimentarios localizados (SIAL), bajo las condicionantes de entorno y contexto actual. Las dinámicas de proximidad explican los procesos de interacción, cooperación y coordinación, subyacentes al desarrollo territorial. En este sentido, los objetivos del trabajo consistieron en construir un modelo de interpretación del desarrollo territorial como proceso societal, con ello analizar las dimensiones de complementariedad entre nueva ruralidad y dinámicas de proximidad, para el desarrollo territorial en los SIAL. La metodología fue un modelo construido de complementariedad conceptual entre nueva ruralidad y dinámicas de proximidad. Se analizaron seis casos SIAL documentados y se postularon seis dimensiones de sincretismo conceptual: capital humano, capital social, competitividad, institucional, gobernanza y dimensión territorial.
\end{abstract}

Palabras clave: Sistemas agroalimentarios localizados, nueva ruralidad, proximidad, desarrollo Territorial.

\section{New rurality and dynamics of proximity in the territorial development of localized agri-food systems}

Abstract: The new rurality as an approach allows the interpretation of the processes of territorial development of localized agri-food systems (SIAL), under the conditions of environment and current context. Proximity dynamics explain the processes of interaction, cooperation and coordination, underlying the territorial development. In this sense, the objectives of the research were to build a model of 
interpretation of territorial development as a societal process, along with analyzing the dimensions of complementarity between new rurality and proximity dynamics related to the territorial development in the SIAL. The methodology was a built conceptual model of complementarity between new rurality and proximity. Six cases of documented SIAL were analyzed and six dimensions of conceptual syncretism were postulated: human capital, social capital, competitiveness, institutional, governance and territorial. development.

Keywords: Localized agri food systems, new rurality, proximity, territorial

\section{Novas dinâmicas Ruralidade e de proximidade no desenvolvimento territorial de sistemas agroalimentares}

Resumo: A nova ruralidade como uma abordagem para interpretar os processos de desenvolvimento territorial de sistemas agroalimentares (SIAL), sob as condições do meioambiente e contextoatual. dinâmica de proximidade explicar os processos de interação, cooperação e coordenação, desenvolvimento territorial subjacente. Neste sentido, os objetivos do trabalho consisti una construção de um modelo de interpretação do ordenamento do território e do processo social, assim, analisar as dimensões da complementaridade entre as novasdinâmicasrurais e de proximidade, para o desenvolvimento territorial no SIAL. A metodologia utilizada foi um modelo conceitual construído a complementaridade entre novas dinâmicas rurais e de proximidade. SIAL documentado seis casos foram analisadose seis dimensões do sincretismo conceitual postulado: capital humano, capital social, competitividade, institucional, governança e dimensão territorial.

Palavras-chave:sistemas agroalimentares, nova ruralidade, de proximidade, de desenvolvimento territorial

$$
* * *
$$

\section{Introducción}

Los espacios rurales han sido considerados habitualmente ámbitos de baja densidad demográfica, con presencia de poblaciones homogéneas respecto a características psico-sociales y donde la agricultura constituyela principal actividad económica. Se han conceptualizado como lugares aislados, atrasados y con rasgos bucólicos e incultos (Echeverri, 2013; Gómez, 2002), definidos por tanto, a partir de la diferenciación dicotómica con los espacios urbanos.

El desarrollo rural, reiteradamente, se ha concebido como transición de lo rural a lo urbano, de lo agrícola a lo industrial, de lo atrasado a lo moderno. Las políticas para el desarrollo rural no han sido la excepción, conllevan implícita o explícitamente un sesgo vinculado con la modernización agrícola o con la mitigación de la pobreza (Grajales y Concheiro, 2009; Pérez, 2004).

La realidad del medio rural no coincide con las concepciones tradicionales. El ámbito se ha transformado de manera radical en las últimas tres 
décadas, tanto por el cambio de régimen de acumulación (industrialización por sustitución de importaciones vs neoliberal) como por intensificación del proceso de globalización, lo que ha modificado estructuras y dinámicas de las sociedades rurales. El marco conceptual de interpretación del medio rural en relación al urbano ha mostrado su incapacidad para responder a la realidad estructurada (Kay, 2009; Pérez, 2004).

Los espacios rurales presentan hoy día una creciente diversificación económica, vinculada a la pérdida de centralidad de la agricultura. Las actividades no agrícolas se han tornado relevantes en términos de empleos e ingresos y las diferencias rurales-urbanas se han desvanecido, para dar paso a una progresiva interacción entre ámbitos. Grajales y Concheiro (2009) aducen elementos que han contribuido a la configuración de nuevas espacialidades: transformaciones en la organización espacial de las actividades productivas, crecimiento de sistemas urbanos, multi-direccionalidad de intercambios migratorios y reconfiguración de mercados laborales. Empero, se atienden también procesos de revalorización de las actividades rurales, lo cual re-direcciona a los ámbitos rurales como alternativa de vida al contribuir a la generación de empleo, reducir la pobreza y favorecer el crecimiento económico (Pérez y Farah, 2002).

En la década de los noventas surge el enfoque de nueva ruralidad, como marco que pretende interpretar la realidad del mundo rural en base al modelo económico de acumulación neoliberal y contextualizar los procesos de desarrollo ante el entorno global. La propuesta del enfoque es integral, con énfasis en la construcción de estrategias, instrumentos y propuestas de acción para el desarrollo rural, pero sin soslayar las limitantes prevalecientes: a) persistencia de pobreza, reproducción de la marginalidad y concentración de ingresos; b) enfoques agraristas dominantes en las políticas rurales; c) procesos de desagrarización; d) acelerado deterioro de ecosistemas; e) contextos de inequidad social, discriminación de género, segregación y desigualdades en oportunidades (Kay, 2009; Pérez, 2004; Echeverri y Ribero, 2002).

La nueva ruralidad constituye una visión interdisciplinaria que reconoce la heterogeneidad económica del ámbito rural y los múltiples vínculos de interdependencia con lo urbano, busca disminuir el sesgo sectorial del desarrollo rural, promover políticas integrales y diferenciadas para la multiplicidad rural, así como conferir visibilidad al peso estratégico de los espacios rurales para el desarrollo (Pérez, 2004). De acuerdo con Echeverri y Ribero (2002, p. 17), la nueva ruralidad se sustenta en la reconsideración de los espacios rurales como población dispersa adscrita al sector agropecuario, para conceptualizarlos como territorios construidos a partir del uso y apropiación de recursos, con procesos productivos, culturales, sociales y políticos.

En la perspectiva de nueva ruralidad, el desarrollo rural debe concebirse con carácter territorial. El territorio explica y describe la dinámica espacial de las relaciones sociales que establecen las personas en los ámbitos 
culturales, sociales, políticos y económicos (Llanos-Hernández, 2010). No es más una porción de tierra delimitada por su complejidad biofísica (relieve, condiciones ambientales, biodiversidad), sino espacio construido socialmente, es decir, sistema de interacciones sociales, históricamente estructuradas y en constante evolución (Riffo, 2013). La cosmovisión de lo rural como territorio insiere una relación funcional de integración entre áreas dispersas y concentraciones urbanas, incluye variedad de sectores económicos interdependientes, aunada a una nueva forma de gestión del desarrollo, sustentada en la autonomía, democracia participativa y autoinstitucionalización (Echeverri y Ribero, 2002).

El territorio constituye un espacio en el que convergen y se entrelazan intereses, identidad y cultura. La acción social, como expresión social, económica, cultural o política, implica la organización de los componentes del espacio geográfico en procesos concretos que buscan el logro de propósitos comunes. De esta forma, espacio y componentes adquieren expresión territorial al facultar pertenencia, apropiación, empoderamiento y adscripción social al espacio geográfico, al tiempo que constituyen la base para la movilización concreta de recursos frente a finalidades también concretas. La trama social, histórica y cultural que caracteriza a los territorios los pondera como agentes de desarrollo (Echeverri y Echeverri, 2009, p.11).

En este sentido, el enfoque territorial del desarrollo trata de responder al reto de garantizar e integrar competitividad económica, bienestar social, cohesión social, equilibrio territorial y sostenibilidad ambiental (Echeverri, et al., 2003; Caravaca, et al., 2005). Reconoce así mismo la capacidad de la sociedad para formularse proyectos colectivos, sobre la base de un aprovechamiento racional de recursos locales, la creación de espacios de participación y organización socio-institucional que permitan movilizar actores y organizaciones. Lo anterior refiere diversos recortes espaciales, así como la articulación de objetivos, recursos y procesos (materiales e inmateriales), adoptando una perspectiva multisectorial e interterritorial para dar cuenta de la complejidad del desarrollo.

Desde una visión territorial, la nueva ruralidad considera elementos centrales del desarrollo: la transformación institucional para fortalecer la democracia; la gobernanza territorial, vía la descentralización y coordinación de actores públicos y privados;lacompetitividad territorial que maximice las potencialidades productivas mediante la utilización racional de los recursos. En suma, constituye un enfoque que demanda el fortalecimiento de capacidades en los actores rurales, es decir, la construcción de capital humano y capital social, que en un principio de progresividad permita la cimentación de procesos de desarrollo endógeno (Echeverri y Ribero, 2002; Schejtman y Berdegué, 2004).

El enfoque de dinámicas de proximidad refiere un marco analítico para comprender fenómenos subyacentes a la interacción de actores. Se fundamenta en la multiplicidad de escalas espaciales donde las personas sitúan sus acciones (Torre y Rallet, 2005, p. 49). La idea central de la pro- 
puesta de proximidad sostiene que las dinámicas de interacción, coordinación y organización entre individuos estarán condicionadas por el grado en que se comparten conocimientos (proximidad cognitiva), instituciones (proximidad institucional), lazos familiares y/o de amistad (proximidad social), la pertenencia a una misma organización (proximidad organizacional) y a un territorio (proximidad territorial), así como en la dimensión espacial, basada en la separación física entre actores (proximidad geográfica).

Las dinámicas de proximidadse encuentran en la base de colaboraciones, de resolución de conflictos, de acuerdos y compromisos alcanzados por distintos actores de un territorio. Es un enfoque que facilita el entendimiento de los procesos de construcción de normas territoriales, formación de redes de cooperación, realización de proyectos comunes, difusión de conocimientos y generación de innovaciones. Permite interpretar los mecanismos mediante los cuales actores de diversa naturaleza contribuyen en la concreción de procesos de desarrollo en los territorios (Torre, 2014). En este sentido, dinámicas de proximidad permiten analizar elementos planteados por la nueva ruralidad como bases del desarrollo territorial (i.e. gobernanza, institucionalidad, territorio, capital social, capital humano y competitividad), porque son elementos que dependen de la interacción social, el diálogo, la sinergia y el consenso.

Respecto a los Sistemas Agroalimentarios Localizados (SIAL), se asumen modelos geográficos de actividades productivas, formados por concentraciones espaciales de pequeñas agroindustrias que elaboran productos artesanales, su distinción es el arraigo histórico y el consumo en mercados locales-regionales. Los SIAL vinculan elementos individuales en un sistema productivo, cuya evolución en términos de consolidación/ desagregación depende de acciones sociales reciprocas como fuerzas de cohesión o repulsión entre elementos, que al tiempo confieren estabilidad relativa y eficacia sistémica (Muchnik, 2012). Los actores sociales del SIAL establecen la complejidad del sistema territorial a través de la interacción en las cadenas productivas, lo que implica relaciones socio-culturales, económico-productivas y político-institucionales.

El desarrollo territorial en los SIAL se asume relativo y temporal, dependiente de las condicionantes de entorno, de contexto y de los cambios que se generan en los sistemas productivos, lo que precisa de un proceso de gestión de las relaciones sociales en lo colectivo. Los procesos de desarrollo territorial precisan de la capacidad colectiva para realizar acciones en común sobre la base de una interpretación de la realidad compartida. La nueva ruralidad permite analizar los procesos de desarrollo de los SIAL inmersos en un contexto en constante transformación. De igual manera, el enfoque de proximidades permite entender los procesos de interacción, cooperación y coordinación subyacentes al desarrollo territorial, no obstante la ausencia de estudios al respecto.

En tal sentido, el eje del presente trabajo es la complementariedad conceptual entre nueva ruralidad y dinámicas de proximidad como medio 
para analizar los procesos de desarrollo territorial en los SIAL. La pregunta guía de la investigación fue ¿Cuál es la complementariedad conceptual entre nueva ruralidad y dinámicas de proximidad para interpretar el desarrollo territorial en los SIAL? Los objetivos consideraron: 1) construir un modelo de interpretación del desarrollo territorial como proceso societal en los Sistemas Agroalimentarios Localizados; 2) analizar las categorías de sincretismo entre nueva ruralidad y dinámicas de proximidad para el desarrollo territorial en los Sistemas Agroalimentarios Localizados.

\section{Metodología}

El estudio se circunscribió al análisis de seis casos documentados de Sistemas Agroalimentarios Localizados en América Latina y cada caso se diferenció con un acrónimo. De esta manera, se analizaron tres SIAL de quesos: Aculco, México “AM” (Castañeda, et al., 2009); Turrialba, Costa Rica “TCR” (Cascante, 2003); Cajamarca, Perú “CP” (Boucher y RequierDesjardins, 2005; Boucher y Guégan, 2004). Se dilucidó un caso orientado a la producción de yuca: Cauca, Colombia “CC” (Sandoval, 2003); Un análisis de la elaboración de bocadillos de guayaba en las provincias de Vélez y Ricaurte, Colombia “VyRC” (Rodríguez y Rangel, 2005). Así como un estudio en la fabricación de pan artesanal en Tecomatlán, México “TM” (López, 2011; López, et al., 2016). En una primera etapa, se identificaron elementos asociados a pilares estructurales de los SIAL y se contextualizaron los procesos de desarrollo considerando tendencias del sector agroalimentario, así como los cambios de injerencia global. Posteriormente, se analizaron los casos SIAL a partir del modelo de complementariedad conceptual entre nueva ruralidad y dinámicas de proximidad, propuesto en la Tabla 1.

Capital humano y proximidad cognitiva constituyen las primeras dimensiones conceptuales de complementariedad. El capital humano es entendido como el conjunto de conocimiento y habilidades de los individuos y es considerado por la nueva ruralidad como un medio esencial para el desarrollo territorial (IICA, 2000). En la formación de capital humano resulta relevante la proximidad cognitiva, como medio de interacción entre actores que comparten una misma base de conocimientos y experiencia. Resulta importante debido a que una transferencia efectiva de conocimientos necesita que la base cognitiva de los actores sea lo suficientemente cercana a los nuevos conocimientos, con el objetivo de poder identificarlos, interpretarlos y explotarlos con éxito. Además, la base de conocimientos también constituye un referente identitario sobre el cual los actores construyen su adscripción hacia una colectividad específica, en este sentido, la pertenencia a una colectividad estará condicionada al nivel de cercanía cognitiva que se tenga. La proximidad cognitiva permite la interacción horizontal, sobre la base de una comprensión mutua. Además, el entendimiento entre actores facilita la interacción y el intercambio de nuevos conocimientos (Boschma, 2005). 
Un segundo sincretismo conceptual está dado por capital social y proximidad social. El primero es entendido en un sentido amplio como el conjunto de valores, organizaciones e instituciones que suscitan relaciones de confianza, cooperación y redes de asociacionismo, es dimensionado por la nueva ruralidad como un recurso promotor del trabajo colectivo, la eficiencia de las organizaciones, el dinamismo socioeconómico y, por tanto, como esencial en el desarrollo territorial. Tiene un carácter intangible y relacional, dado que se refiere a vinculaciones entre personas o grupos y sólo existe cuando se comparte. Resulta relevante porque favorece procesos de organización social indispensables para reforzar el protagonismo y empoderamiento de los actores de la sociedad, permitiéndoles decidir y gestionar sus propios proyectos de desarrollo.

En este sentido, proximidad social cobra interés puesto que puede propiciar la formación de redes de cooperación que constituyen una parte significativa del capital social. Se trata de una dimensión de proximidad considerada en términos de arraigo, es decir, dos actores son cercanos porque comparten relaciones que implican confianza, basadas en la amistad, parentesco o experiencia. Este tipo de proximidad, facilita el intercambio de conocimiento tácito que es, por naturaleza, mucho más difícil de comunicar. Al cimentarse en la confianza, estimula a los actores a participar en la comunicación, lo que resulta en derrames de conocimiento "boca a boca” (Mattes, 2012; Boschma, 2005). En términos de construcción del territorio, la proximidad social facilita el componente afectivo que integra la identidad colectiva.

Un tercer espacio de articulación conceptual está dado por la visión de competitividad en nueva ruralidad y las dimensiones geográfica, cognitiva y organizacional de proximidad. Competitividad, se considera en términos de Echeverri, et al. (2003, p. 4) como la capacidad para producir y mantener el máximo de valor agregado en el territorio mediante el refuerzo de los vínculos entre sectores y haciendo que la combinación de recursos conduzca a la conformación de activos que valoricen el carácter específico de los productos y servicios locales. En el marco de la nueva ruralidad se concede una priorización a la competitividad como medio para articular con éxito la economía del territorio a mercados dinámicos (Schejtman y Berdegué, 2004). La competitividad dirime tanto ventajas comparativas como competitivas, las primeras están relacionadas con la posesión de determinados factores productivos que explican la especialización geográfica en determinados sectores económicos, las segundas se vinculan con la habilidad para innovar en la utilización y valorización recursos, en aras de conferir valor agregado de largo plazo.

En correlación la proximidad geográfica permite entender las dinámicas vinculadas a la concentración de actividades económicas en áreas específicas. Sus potencialidades se relacionan con externalidades de conocimiento, como experiencias innovadoras que pueden ser absorbidas casi sin costo (por observación), el acceso a infraestructura o la presencia de proveedores especializados. La proximidad cognitiva se torna relevante, al cons- 
tituir un medio de interacción para actores que comparten una misma base de conocimientos y experiencia, al tiempo que se promueve la capacidad para generar innovaciones. Por su parte, la organizacional facilita la interacción en red actuando como vehículo para la transferencia e intercambio de conocimientos, y como promotora del aprendizaje interactivo.

\section{Tabla 1. Complementariedad conceptual entre nueva ruralidad y dinámicas de proximidad.}

\begin{tabular}{|c|c|c|}
\hline Nueva ruralidad & Descripción & Proximidad \\
\hline Capital humano & $\begin{array}{c}\text { Conocimiento y habilidades de los individuos para } \\
\text { transformar el sistema socio-económico y reaccionar a } \\
\text { los desafios externos }\end{array}$ & Cognitiva \\
\hline Capital social & $\begin{array}{c}\text { Valores, organizaciones e instituciones que suscitan } \\
\text { relaciones de confianza, cooperación y redes de } \\
\text { asociacionismo }\end{array}$ & Social \\
\hline Competitividad & Ventajas comparativas y competitivas. & $\begin{array}{c}\text { Geográfica, } \\
\text { Cognitiva y } \\
\text { Organizacional }\end{array}$ \\
\hline Institucionalidad & Actores comparteninstituciones formales y/o informales & \begin{tabular}{c} 
Institucional \\
\hline Gobernanza
\end{tabular} Actores diversos se coordinan para la construcción de \\
procesos de desarrollo & $\begin{array}{c}\text { Organizacional e } \\
\text { institucional }\end{array}$ \\
\hline Lógica territorial & Espacio construido social e históricamente & Territorial \\
\hline
\end{tabular}

Fuente: Elaboración propia.

Una cuarta relación de complementariedad es la de institucionalidad y proximidad institucional. La primera es vista por la nueva ruralidadcomo formas de regulación y organización formal e informal en el territorio, acuerdos, compromisos, normas, competencias, roles y organizaciones, tanto públicas como privadas. Considera los diversos intereses, decisiones e incentivos de todos los actores del territorio (económicos, políticos y sociales) y reconoce procesos alrededor de los cuales se estructuran las transformaciones institucionales: 1) la descentralización, que busca la generación y promoción de autonomías de los espacios locales; 2) la globalización e integración regional, como expresión del desplazamiento de competencias a esferas supranacionales; 3) la privatización, como expresión de la entrega de responsabilidades a los agentes privados y colectivos, y 4) la participación, como expresión de nuevos espacios de autogestión de la ciudadanía y un nuevo relacionamiento entre la sociedad civil y el Estado (Echeverri y Ribero, 2002).

Nueva ruralidad propugna porque la participación local, el empoderamiento y la cooperación sean mecanismos para el fortalecimiento gradual de una institucionalidad que estimule la concertación entre actores públicos y privados, modifique instituciones que reproducen la exclusión, 
aumente la transparencia de la gestión pública y garantice la legitimidad y credibilidad en la gobernabilidad (Echeverri y Ribero, 2002). En este orden de argumentación, la proximidad institucional entendida como el grado en el que un conjunto de actores comparten instituciones formales y/o informales, permite la comprensión de los procesos de institucionalidad en el marco de una nueva ruralidad.Ésta dimensión de proximidad promueve el diálogo, la coordinación de actores y el trabajo colectivo, a través de la reducción de incertidumbre y costos de transacción, proporcionando condiciones estables para la interacción social (Boschma, 2005).

En quinto lugar, se considera el complemento entre gobernanza y las dimensiones organizacional e institucional de proximidad. La gobernanza constituye el conjunto de procesos y mecanismos promovidos por la nueva ruralidad mediante los cuales actores de diversa naturaleza se coordinan para la construcción de procesos de desarrollo. Implica la participación de actores con preferencias heterogéneas en el proceso de decisión y conlleva la búsqueda de un equilibrio entre fuerzas de cooperación y conflicto. La gobernanza busca la forma de conciliar puntos de vista opuestos y de hacer que las diferentes partes involucradas trabajen en conjunto, con el fin de realizar proyectos que beneficien a los territorios (Torre, 2014).

Por su parte, las dimensiones organizacional e institucional de proximidad permiten entender los procesos de cooperación y/o conflicto subyacentes en la gobernanza. Por un lado, la pertenencia a una misma organización facilita el surgimiento del diálogo entre actores y la construcción de redes de cooperación. Por el otro, los valores y normas en común son esenciales para iniciar la coordinación de actores, porque permiten la aceptación de reglas inmersas en el proceso de gobernanza. Tanto la proximidad organizacional como la institucional permiten manejar la tensión y el conflicto, crear alianzas y lenguajes comunes, refinar puntos de vista, negociar y formular proposiciones construidas sobre bases compartidas (Torre, 2014).

Por último, se contempla la articulación entre lógica territorial y proximidad territorial. La noción territorial de la nueva ruralidad conlleva una asimilación de la integralidad y funcionalidad de diversos sectores económicos y patrones demográficos de ocupación. El territorio es una construcción social que tiene carácter histórico y que se refleja en una cultura expresada como identidad territorial. La visión territorial, reconoce que cualquier dinámica del territorio se superpone o interrelaciona con procesos emanados en distintas escalas geográficas (globales, nacionales, regionales y locales). Esto implica una consideración más compleja de los procesos de negociación, coordinación y gobernanza. Es el caso de las cadenas o redes de producción agroindustrial, que conectan diversos lugares y escalas, generando complejos procesos de gobernanza público-privada.

En este sentido, la idea de proximidad territorial permite la comprensión de las dinámicas de interacción que construyen los territorios. Se trata de una dimensión que pondera la articulación de diferentes actividades que se desarrollan en espacios discontinuos. El territorio actúa como factor de 
ensamblaje, es decir, como actor que posee memoria y cualidades para organizar estrategias colectivas. La proximidad territorial conlleva la capacidad de formular y coordinar proyectos de naturaleza sistémica, vía la integración colectiva de los actores territoriales tanto públicos como privados. La cualidad del territorio como ensamblador (Muchnik, 2012) se constata con la solidaridad territorial, los sentimientos de pertenencia y los valores comunes que estructuran y dan significado a las redes sociales.

\section{Resultados y discusión}

Los SIAL constituyen sistemas territoriales complejos que interrelacionan diversos elementos (i.e. agroindustrias rurales (AIR), actores, instituciones, saber-hacer, territorio, recursos específicos, redes de interacción) actuando como totalidad organizada. Se sustentan en tres pilares socio-productivos: agropecuario, alimentario y de concentración (ver Tabla 2). El primero opera como proveedor de materia prima, sustentado en los recursos específicos locales, y relacionado con la AIR por medio de la comercialización. Se trata de sistemas de producción campesinos, con productores minifundistas que disponen de dos a tres hectáreas de superficie agrícola y monocultivos asociados. No obstante la especificidad de la materia prima para la fabricación de productos, la constante que lo define es su escasa relación horizontal, dificultad para integrarse verticalmente y la inequidad en la redistribución del ingreso. Los productores primarios son los de mayor inversión y riesgo en la actividad agroalimentaria, respecto a los beneficios.

El pilar alimentario detenta la valorización de productos característicos de un territorio, vía la tradición, fama y prestigio, que lo posicionan en el mercado. En este caso, la calidad de los alimentos es una percepción del consumidor, pero también es construcción social colectiva en busca de especificidad y trazabilidad. Las empresas de transformación son de tipo agroindustria rural, con uso de tecnología tradicional, equipos rudimentarios, adecuación de instalaciones y empleo de mano de obra familiar. La elaboración artesanal y el origen de la materia prima, aportan características específicas a los alimentos y constituyen un elemento diferenciador respecto alimentos industrializados. La comercialización se dirige al mercado local-regional, pero el proceso concatena relaciones horizontales, verticales y transversales. Se podría aducir que los SIAL vinculan sector primario con mercado por medio de una economía empresarial de enclave.

El pilar de concentración de AIR pondera localización de recursos y activos específicos, la proximidad geográfica de los actores sociales, particularidad de actividades económicas, economías externas, espacialidadtemporalidad y tipos de mercado. Sin embargo, las concentraciones no solo se definen por la localización respecto al mercado, favorecen difusión de conocimientos e información, articulan actividades como los servicios de suministro o profesionales y posibilitan la distribución del ingreso agrícola. La interrelación entre actividades agropecuarias y agroindustriales consti- 
tuye un elemento estructurador de los SIAL, que produce esquemas de organización heterogéneos, existen SIAL donde las producción agropecuaria y agroindustrial están integradas a una misma unidad de producción (TCR), otros casos donde están separadas (TM, AM, CP, VyRC) y algunos donde se combinan unidades integradas y separadas (CC).

Tabla 2. Pilares que sustentan los SIAL

\begin{tabular}{|c|c|c|c|}
\hline $\begin{array}{l}\text { SIAL } \\
\text { Pilar }\end{array}$ & Agropecuario & Alimentario & Concentración \\
\hline CP & $\begin{array}{l}\text { Existen aproximadamente } \\
30,000 \text { productores de leche, } \\
\text { que poseen } 4 \text { o } 5 \text { vacas. Se } \\
\text { estima una producción diaria } \\
\text { de } 503,000 \text { litros, siendo la } \\
\text { segunda o tercera cuenca } \\
\text { lechera de Perú. }\end{array}$ & $\begin{array}{l}\text { Elaboran queso andino tipo suizo, } \\
\text { queso fresco y queso mantecoso. } \\
\text { Este último es el producto } \\
\text { "típico" de Cajamarca, su } \\
\text { fabricación es reflejo de una } \\
\text { tradición y un saber-hacer } \\
\text { ancestral. }\end{array}$ & $\begin{array}{l}\text { Se tiene alrededor de } \\
19,000 \text { productores } \\
\text { de quesillo (insumo } \\
\text { del mantecoso). } \\
\text { Se tiene } 157 \\
\text { productores de queso } \\
\text { andino tipo suizo; } 98 \\
\text { productores de } \\
\text { mantecoso y } 205 \\
\text { productores de queso } \\
\text { fresco. }\end{array}$ \\
\hline TCR & $\begin{array}{l}\text { Las agroindustrias integran la } \\
\text { producción lechera y } \\
\text { elaboración de queso. } \\
\text { Son fincas-queseras con un } \\
\text { tamaño promedio de } 7 \text { ha. }\end{array}$ & $\begin{array}{l}\text { Elaboran quesos frescos, ricos en } \\
\text { grasa y de color amarillo claro, } \\
\text { elaborados con leche entera y } \\
\text { pueden ser suaves o prensados. } \\
\text { El queso de Santa Cruz posee una } \\
\text { fama y prestigio bien } \\
\text { posicionados en el mercado } \\
\text { nacional. }\end{array}$ & $\begin{array}{lr}\text { Existen } & 150 \\
\text { productores de } & \text { de } \\
\text { quesos artesanal } \\
\text { (empresa familiar) y } \\
\text { 18 mini-plantas. Que } \\
\text { obtienen } 120 \\
\text { toneladas mensuales } \\
\text { de queso. }\end{array}$ \\
\hline AM & $\begin{array}{l}\text { Se tienen } 266 \text { productores de } \\
\text { leche. Estos aportan } 14,447 \\
\text { litros diarios. Cuentan con un } \\
\text { promedio de } 9 \text { vacas de raza } \\
\text { holstein o cruzas con suizo. } \\
\text { Integran la producción } \\
\text { agricola con la ganadera. }\end{array}$ & $\begin{array}{l}\text { Elaboran quesos diferenciados por } \\
\text { el proceso productivo (oaxaca, } \\
\text { molido, manchego, panela, } \\
\text { provolone y de morral). El queso } \\
\text { molido es el de mayor tradición. }\end{array}$ & $\begin{array}{l}\text { La elaboración de } \\
\text { quesos deriva de un } \\
\text { conjunto de } 37 \\
\text { agroindustrias. La } \\
\text { producción semanal } \\
\text { se estima en } 43,209 \\
\mathrm{~kg} \text {. }\end{array}$ \\
\hline TM & $\begin{array}{l}\text { Se estima un consumo } \\
\text { semanal de } 21,500 \mathrm{~kg} \text { de } \\
\text { harina de trigo provenientes } \\
\text { de la región bajío y norte de } \\
\text { México. }\end{array}$ & $\begin{array}{l}\text { Elaboran pan artesanal, con más } \\
\text { de } 100 \text { años de tradición. Sus } \\
\text { principales características son la } \\
\text { ausencia de aditivos químicos y el } \\
\text { uso de leña y homos de piedra } \\
\text { para la cocción. }\end{array}$ & $\begin{array}{l}\text { Se tiene una } \\
\text { concentración de } \\
117 \text { agroindustrias } \\
\text { en un espacio de } 0.8 \\
\mathrm{~km}^{2}\end{array}$ \\
\hline VyRC & $\begin{array}{l}\text { Se estiman } 3,625 \text { productores } \\
\text { de guayaba, que tienen un } \\
\text { área media de } 6.31 \text { ha. La } \\
\text { producción de guayaba se } \\
\text { estima en } 81,800 \text { toneladas } \\
\text { anuales y } 25,500 \text { toneladas se } \\
\text { destinan a la fabricación del } \\
\text { bocadillo. }\end{array}$ & $\begin{array}{l}\text { El bocadillo es una pasta } \\
\text { resultante de la mezcla de } \\
\text { guayabas y azúcar. Empacado en } \\
\text { hoja de "bijao", especie cultivada } \\
\text { en la región. La denominación de } \\
\text { "bocadillo veleño" es reconocida } \\
\text { a nivel nacional. }\end{array}$ & $\begin{array}{l}\text { Existen } 131 \text { fábricas } \\
\text { de bocadillo en la } \\
\text { región. Producen } \\
\text { alrededor de } 24,300 \\
\text { toneladas al año de } \\
\text { bocadillo de } \\
\text { guayaba. }\end{array}$ \\
\hline $\mathrm{CC}$ & $\begin{array}{l}\text { Existen } 5000 \text { productores de } \\
\text { yuca. Tienen entre } 2.5 \text { y } 3.5 \\
\text { ha. Cultivan la yuca asociada } \\
\text { con maíz y frijol. }\end{array}$ & $\begin{array}{l}\text { Almidón agrio de Yuca. Bien } \\
\text { intermedio que se utiliza como } \\
\text { materia prima en la panificación. }\end{array}$ & $\begin{array}{lr}\text { Existen } & 210 \\
\text { agroindustrias } & \\
\text { (rallanderías). } & \\
\text { Generan } & 827 \\
\text { empleos directos. }\end{array}$ \\
\hline
\end{tabular}

Fuente: Elaboración propia, con datos de estudios de caso SIAL 
Los SIAL se encuentran inmersos en procesos que condicionan su desarrollo. A partir de década de 1980, el proceso de ajuste estructural significó apertura comercial, desregulación de mercados y descentralización. Lo anterior sumado a la intensificación del proceso globalizador ha marcado un nuevo escenario socioeconómico: un sistema agroalimentario mundial más integrado, dominio de empresas transnacionales, nuevas exigencias de calidad del consumidor y nuevas formas de gobernanza entre los implicados en la cadena agroalimentaria (Boucher, 2012). El proceso de globalización incide en el espacio-tiempo con la tecnología. Experiencias o simbolismos se adjetivan de manera simultánea en diferentes lugares y redes sociales; telecomunicaciones e informática facilitan organizar procesos de gestión, transporte o logística; producción y distribución se digitalizan; formación profesional e información en línea posicionan en los circuitos de comercialización (Muchnik, 2012).

El desarrollo territorial de los SIAL es determinado por tiempo-espacio de configuración socio-espacial, dependiente del entorno (condiciones económicas, productivas, sociales, culturales, políticas, institucionales) y contexto (globalización, políticas de ajuste estructural). De igual manera, es dependiente de las interacciones entre los componentes que estructuran el sistema y de la capacidad colectiva para realizar acciones en común sobre una misma interpretación de la realidad y de sus posibilidades de cambio. En este orden de ideas, la complementariedad conceptual entre nueva ruralidad y proximidad se traduce en una nueva mirada que contribuye la interpretación y explicación del desarrollo territorial en los SIAL.

\section{Capital humano - Proximidad Cognitiva}

De acuerdo con Boisier (2005, p. 54), el desarrollo constituye por definición un proceso endógeno que sólo compete en su concepción, diseño e implementación a la colectividad de determinado territorio. En este sentido, el impulso del capital humano implica: incrementar la capacidad de los actores para transformar el sistema socio-económico; ampliar la destreza para reaccionar a los desafíos externos; la promoción de aprendizaje social; el empoderamiento para acceder a mecanismos y espacios de gestión del desarrollo.

El capital humano en los SIAL constituye el potencial endógeno para el desarrollo. Las capacidades de productores agroindustriales tienen un rol central como elementos base para realizar transformaciones productivas y socio-institucionales, pues determinan el potencial para reconocer, asimilar, aplicar y generar nuevos conocimientos. Los SIAL analizados se caracterizan por la presencia de productores con bajos niveles de escolaridad, primaria o secundaria, sólo en CP muestran estudios universitarios. No obstante, se tiene presencia de productores líderes que encabezan procesos de organización orientados a producir cambios y con capacidades para negociar o tomar decisiones respecto a proyectos de desarrollo. 
Tabla 3. Complementariedad de nueva ruralidad y proximidad en SIAL

\begin{tabular}{|l|l|c|c|c|c|c|c|}
\hline \multicolumn{1}{|c|}{$\begin{array}{c}\text { Complemento } \\
\text { conceptual }\end{array}$} & \multicolumn{1}{|c|}{ Indicadores } & CP & TCR & AM & TM & VyRC & CC \\
\hline $\begin{array}{l}\text { Capital humano-- } \\
\text { proximidad } \\
\text { cognitiva }\end{array}$ & $\begin{array}{l}\text { Presencia de un saber-hacer con } \\
\text { arraigo territorial y transmitido } \\
\text { generacionalmente. }\end{array}$ & $\mathrm{Si}$ & $\mathrm{Si}$ & $\mathrm{Si}$ & $\mathrm{Si}$ & $\mathrm{Si}$ & $\mathrm{Si}$ \\
\cline { 2 - 7 } Productores agroindustriales con & $\mathrm{Si}$ & $\mathrm{No}$ & $\mathrm{No}$ & $\mathrm{No}$ & $\mathrm{No}$ & $\mathrm{No}$ \\
\hline preparación universitaria.
\end{tabular}

Fuente: elaboración propia, con datos de estudios de caso SIAL.

La proximidad cognitiva entre productores se relaciona con la construcción de un saber-hacer tradicional de larga data (100 años para TM y VyRC), transmitido de manera generacional o por relaciones sociales de amistad y de intercambio comercial. Se trata de conocimientos tácitos de origen endógeno, que han evolucionado a partir de un proceso recursivo de prueba y error. El saber-hacer está arraigado en el territorio y la característica que lo define es su anclaje territorial. Esta forma de proximidad se concreta básicamente por la interacción horizontal, sobre la base de una comprensión mutua, donde el entendimiento entre productores facilita interacción e intercambio de conocimientos.

\section{Capital Social - Proximidad Social}

El capital social en los SIAL se vincula con la proximidad social, auspiciada por relaciones sociales de parentesco y amistad, aunque no se descartan las establecidas con fines comerciales. Las relaciones sociales 
están basadas en procesos-actitudes de confianza y reciprocidad. En todos los SIAL estudiados, las labores de producción corresponden al núcleo familiar, donde el saber-hacer de la actividad agroalimentaria es transmitido de padres a hijos. La proximidad social entre productores facilita las actividades de intercambio y cooperación, sean préstamos de equipos, materiales o materia prima, intercambios de información o compras conjuntas. Estos acuerdos operan de manera tácita e implícita y se basan en la disposición de los actores para comunicarse. La proximidad social promueve la cohesión en el SIAL, compartir relaciones de amistad, parentesco, experiencia, sentimientos y emociones permite crear una identidad compartida.

Todos los casos analizados presentaron formación de organizaciones de productores. Se trata de asociaciones que direccionan sus acciones al acceso a financiamientos o capacitación, compras y ventas en bloque, obtención de marcas y registros sanitarios. Al pertenecer a una misma organización, se facilitan las interacciones, se promueven los procesos de coordinación sobre la base de una misma interpretación de normas y se favorece el intercambio de información y conocimientos entre socios, facilitando el aprendizaje y la innovación. Tales organizaciones constituyen un mecanismo que fortifica el protagonismo de los productores en la demanda de bienes y políticas para el desarrollo territorial. Permiten representar, ante terceros, intereses comunes, creando capacidad de gestión y formando grupos de presión que les abren espacios adecuados en las instancias donde se toman decisiones que les afectan (Echeverri y Ribero, 2002).

\section{Competitividad - Proximidad cognitiva, geográfica y organizacional}

La competitividad de los SIAL dirime tanto ventajas comparativas como competitivas. Se puede decir que en los casos de estudio, las ventajas comparativas están suscritas a tres tipos de factores: a) los espaciales, que especifican la cercanía física (proximidad geográfica) de los sistemas productivos locales con los sitios de abastecimiento de la materia prima y los núcleos de comercialización, lo que proporciona ventajas en términos de distancia/tiempo y distancia/costo; b) los naturales, que constituyen la base de elementos que sostienen las actividades agropecuarias (suelos, clima, variedades vegetales, hidrografía) y posibilitan la provisión de la materia prima para la producción agroindustrial; c) la infraestructura física constituida por la red de carreteras, presas, canales de riego, electricidad y telecomunicaciones, lo cual condiciona la adquisición de insumos, producción y comercialización, así como la interacción entre actores sociales (tipos de proximidad).

Las ventajas competitivas están relacionadas con la habilidad para utilizar o movilizar recursos, representan los elementos incorporados que aportan valor añadido a la producción agroalimentaria y permiten su permanencia a través del tiempo. Empero, estas ventajas son consecuentes al esfuerzo permanente en la introducción de innovaciones, (Barroso y Flores, 2006; Caravaca, et al., 2005). La relevancia de la innovación en producto se reflejó en la constante consecución de valor agregado de estos produc- 
tos agroalimentarios (diversificación de productos, uso de etiquetas, nuevos empaques, uso de registros sanitarios). En proceso se busca mayor eficiencia e incremento de la escala productiva(introducción de nuevos equipos o maquinaría). En organización se han adquirido nuevas habilidades administrativas para el cálculo de costos de producción, sondeo de mercados, determinación de eficiencia del proceso productivo o rendimiento de materia prima. En mercado se busca constantemente la apertura de nuevos canales de comercialización (supermercados, ferias agroalimentarias) y el empleo de publicidad.

La proximidad cognitiva entre productores del SIAL, promueve la comprensión mutua, interacción e intercambio de conocimientos. Al ser conocimientos tácitos lo que se comparten, las innovaciones se generan en las relaciones sociales informales y en el trabajo diario, son por tanto innovaciones de tipo incremental, dirigidas a producto (diversificación) o proceso (cambios tecnológicos). La proximidad organizacional permite al conjunto de actores de cada SIAL formar una unidad estructurada de relaciones, con vínculos que constituyen una red o arquitectura de conexiones del sistema productivo al tiempo que se establecen los canales donde circula información y conocimiento, además del aprendizaje en el ámbito productivo y comercial.

\section{Institucionalidad - Proximidad institucional}

En el ámbito institucional los SIAL presentan compartición de normas, rutinas y prácticas sociales relacionadas con la producción agroalimentaria, con interacciones sustentadas en valores de confianza y reciprocidad. Las relaciones sociales están adscritas a la cadena productiva, hacia atrás para la provisión de materia prima y compra de insumos, hacia adelante, para la venta de productos, sin olvidar la necesaria relación horizontal. En las relaciones de los productores con proveedores y clientes también predominan valores de confianza, es decir, se trata de relaciones económicas de palabra, sin intermediación de contratos, y en algunos casos se otorgan créditos para cubrir parte de los pagos de materia prima y producto terminado (CC, AM, TM, VyRC).

En el marco de los procesos de cambio institucional vinculados a modificaciones de competencias entre diferentes niveles del territorio. La proximidad institucional en los SIAL promueve alianzas entre sistemas de representación ubicados en distintas escalas espaciales, ayudando en la construcción de una nueva institucionalidad. Las normas en común facilitan el diálogo, la coordinación y el trabajo colectivo entre los diferentes actores involucrados en la producción agroalimentaria, a través de la reducción de incertidumbre y costos de transacción, proporcionando condiciones estables para la interacción social (Boschma, 2005). De tal suerte que fortalecen la formación de redes de cooperación informal, las asociaciones de productores, la ejecución de proyectos colectivos, constituyéndose esquemas favorables al empoderamiento, la participación y cooperación local y expresando tendencias cada vez 
más claras hacia la autonomía, la autogestión y la auto-institución (Echeverri y Ribero, 2002).

\section{Gobernanza - Proximidad institucional y organizacional}

La gobernanza de los SIAL está adscrita a procesos de relación horizontal-vertical-transversal, de integración horizontal-vertical y de coordinación a nivel territorial. Los primeros hacen referencia a la organización del sistema productivo. La proximidad organizacional esgrime relaciones socioeconómicas y productivas intra e interdependientes; las horizontales que se llevan a cabo entre productores agroindustriales, las verticales entre proveedores de insumos, productores agrícolas, intermediarios y clientes, así como las transversales (instituciones, ONG, organismos internacionales).

La integración horizontal-vertical se presenta a través de procesos de acción colectiva entre AIR para la comercialización conjunta, conlleva crear "integradoras” o “comercializadoras” que permiten externalizar operaciones y obtener formas flexibles de comercialización para reducir costos de operación y adaptarse de mejor forma a los constantes cambios del mercado. La coordinación territorial en los SIAL busca satisfacer necesidades específicas, vía la corresponsabilidad. Esto ha redundado en la promoción conjunta de las producciones, organización de ferias agroalimentarias (TCR) o regulación de las actividades productivas (CC). Son procesos que se ven facilitados por la proximidad organizacional e institucional, la pertenencia a una misma asociación de productores facilita el diálogo y la construcción de redes de cooperación. Los hábitos, valores y tradiciones comunes permiten manejar la tensión y el conflicto, crear alianzas y lenguajes comunes, refinar puntos de vista, negociar y formular proposiciones construidas sobre bases compartidas (Torre, 2014).

\section{Lógica territorial - Proximidad territorial}

Finalmente, en la dimensión territorial, los SIAL presentan una construcción socia-histórica que pondera funcionamiento, evolución y adaptación en el tiempo (entre 60 y 100 años de producción); incide en tres aspectos: 1) transmisión generacional de saber-hacer y conocimientos tácitos, que configuran cultura productiva, tradición y tipificidad de productos; 2) conformación de redes sociales institucionalizadas de intercambio; 3) respuesta a cambios de entorno con procesos de expansión (transición de unidades de producción domesticas hacia agroindustriales; modificación de las cadenas de valor con propuestas de mercado justo, orgánico o de productos "light”).

El territorio en los SIAL provee condiciones de entorno para el desarrollo, favorece lógicas de aprendizaje, cooperación, coordinación y procesos de multiplicación de iniciativas, producto de la comunicación a media palabra, de la relación informal e implícita, cuya base es una relación interpersonal fuerte y una historia de vínculo social (Boisier, 2010). En este 
sentido, la proximidad territorial es una dimensión que se caracteriza por la especificidad del territorio de cada SIAL, pero pondera la articulación de diferentes actividades que se desarrollan en espacios discontinuos (producción de materia prima, procesamiento y comercialización).

Condensa, articula y superpone todas las dimensiones de proximidad, lo que repercute en procesos de innovación, organización, y coordinación. Establece co-presencia de actores en el SIAL, órdenes relacionales, consolidación de prácticas culturales e institucionales, conocimientos e identidad compartida colectivamente. El territorio dilucida con las prácticas sociales lo producido por generaciones, de esta manera vincula historia con espacio en momento y contexto dado; además, estructura relaciones sociales con hechos, crisis y rupturas experimentadas, (Castañeda, et al., 2012). Las diferentes formas de proximidad definen las escalas de acción de los actores del SIAL, circunscribiendo así su territorio. El territorio SIAL resulta de y se define por la transposición de las diferentes dimensiones de proximidad, constituyendo un sistema territorial complejo. De esta forma, se establecen los mecanismos territoriales de coordinación e interrelación entre actores, a través de procesos que incluyen la colaboración, el intercambio de las redes sociales, las sanciones colectivas, la concentración de la información, los códigos informales, la frecuencia de los contactos y la construcción de relaciones de confianza (Tremblay, et al., 2004).

\section{Conclusiones}

Nueva ruralidad y dinámicas de proximidad ofrecen dimensiones conceptuales complementarias, capaces de interpretar los procesos de desarrollo territorial en los SIAL. El sincretismo conceptual permite entender la construcción social del desarrollo bajo las condicionantes actuales de entorno y contexto. El capital humano en los SIAL, asociado a una proximidad cognitiva, constituye el potencial endógeno para el desarrollo, permite realizar transformaciones productivas y socio-institucionales. El capital social se vincula a existencia de una proximidad social, auspiciada por relaciones de parentesco, amistad y confianza, facilita las actividades de intercambio y cooperación, constituyendo un mecanismo que fortifica el protagonismo de los productores en la gestión de proyectos para el desarrollo territorial.

La competitividad de los SIAL conlleva la utilización y movilización de los recursos territoriales para conferir valor agregado de largo plazo, incluye tanto ventajas comparativas como competitivas, las primeras se refieren a factores de proximidad geográfica (espaciales, naturales y de infraestructura), las segundas son resultado de la introducción recurrente de innovaciones, vía la proximidad cognitiva y organizacional. En lo institucional, las reglas, hábitos y valores en común reducen la incertidumbre y promueve el diálogo, coordinación y trabajo colectivo entre actores, el surgimiento de redes de cooperación, de asociaciones de productores y la ejecución de proyectos colectivos que fortalecen la institucionalidad territorial. 
La gobernanza de los SIAL está adscrita a procesos de relación horizontal-vertical-transversal, de integración horizontal-vertical y de coordinación a nivel territorial. Son dinámicas que se ven facilitadas por la proximidad organizacional e institucional, la pertenencia a una misma organización y las normas en común facilitan el diálogo entre actores y la construcción de redes de cooperación. La gobernanza permite el trabajo conjunto de actores en pro de proyectos para el desarrollo de los territorios. Finalmente, las diferentes formas de proximidad definen las escalas de acción de los actores del SIAL, circunscribiendo así su territorio. El territorio SIAL resulta y se define por la transposición de las dimensiones de proximidad, constituyendo un sistema territorial complejo. Provee condiciones de entorno para el desarrollo, favorece lógicas de aprendizaje, cooperación, coordinación y procesos de multiplicación de iniciativas. 


\section{Nota}

${ }^{1}$ Este trabajo fue realizado gracias al apoyo del Programa de becas posdoctorales en la UNAM, a través del Instituto de Investigaciones Sociales. 
Polis, Revista Latinoamericana, $N^{\circ}$ 47, 2017

\section{Bibliografía}

Barroso, M. y Flores, D. (2006). La competitividad internacional de los destinos turísticos: del enfoque macroeconómico al enfoque estratégico. Cuadernos de Turismo, (17), 7-24. Recuperado de http:// www.redalyc.org/articulo.oa?id=39801701

Boisier, S. (2005). ¿Hay espacio para el desarrollo local en la globalización? Revista de la CEPAL, (86), 47-62. Recuperado de http:// repositorio.cepal.org/bitstream/handle/11362/11068/1/ 086047062_es.pdf

Boisier, S. (2010). Descodificando el desarrollo del siglo XXI: subjetividad, complejidad, sinapsis, sinergia, recursividad, liderazgo, y anclaje territorial,Semestre Económico,13, (27), 11-37. Recuperado de http:/ /revistas.udem.edu.co/index.php/economico/article/view/255/238

Boschma, R. (2005). Proximity and Innovation: A Critical Assessment. Regional Studies,39 (1), 61-74.doi: 10.1080/0034340052000320887

Boucher, F. y Guégan, M. (2004).Queserías Rurales de Cajamarca futuro de la quesería rural de Cajamarca. Intermediate Technology Development Group, ITDG - Perú, 195 p. Recuperado de http:// ciat-library.ciat.cgiar.org/articulos_ciat/Queserias_Rurales _en_Cajamarca.pdf

Boucher, F. y Requier-Desjardins, D.(2005).La concentración de las queserías rurales de Cajamarca: retos y dificultades de una estrategia colectiva de activación.Agroalimentaria, 10, (21) 13-27. Recuperado de http://www.redalyc.org/articulo.oa?id=199216552001

Boucher, F. (2012). Reflexiones en torno al enfoque SIAL: evolución y avances desde la Agroindustria Rural (AIR) hasta los Sistemas Agroalimentarios Localizados (SIAL). EnG. Torres, y R. M. Larroa (Coord.). Sistemas Agroalimentarios Localizados, Identidad Territorial, Construcción de Capital Social e Instituciones. (pp. 43-68). México, UNAM.

Caravaca, I., González, G. y Silva, R. (2005). Innovación, redes, recursos patrimoniales y desarrollo territorial. Revista EURE, 31 (94), 5-24. Recuperado de http://www.eure.cl/index.php/eure/article/view/1332

Cascante, M. (2003).Concentración de queserías en las faldas del Volcán Turrialba. Informe final. Prodar, Universidad Nacional de Costa Rica, Costa Rica. Recuperado de http://territorioscentroamericanos.org/ sites/default/files/Concentraci\%C3\%B3n\%20de\%20queser\%C3\% ADas\%20en\%20las\%20faldas\%20del\%20volc\%C3\%A1n\%20Turrialba_0.pdf 
Castañeda, T., Boucher, F., Sánchez, E. y Espinoza, A. (2012). El papel de la proximidad geográfica y la organizada en la construcción de una estrategia colectiva vinculada a la agroindustria quesera rural. En G. Torres, y R. M. Larroa (Coord.). Sistemas Agroalimentarios Localizados, Identidad Territorial, Construcción de Capital Social e Instituciones. (pp. 199-223). México DF., México: UNAM.

Castañeda, T., Boucher, F., Sánchez, E. y Espinoza, A. (2009). La concentración de agroindustrias rurales de producción de quesos en el noroeste del Estado de México: un estudio de caracterización.Estudios Sociales, 17 (34) 74-109. Recuperado de http://www.autores.redalyc. org/articulo.oa?id=41711502003

Echeverri, R. (2013). Los nuevos conceptos de ruralidad, el enfoque territorial del desarrollo rural y políticas públicas en América Latina y Reflexiones sobre el ordenamiento territorial y los planes de desarrollo rural territorial. Curso de Actualización Conceptual y Metodológico en Gestión del Desarrollo Territorial, IICA-PROTERRITORIOS, Mendoza, Argentina, 15 al 18 de octubre de 2013,

Echeverri, R. y Echeverri, A. M. (2009). El enfoque territorial redefine el desarrollo rural. Seminario Institucionalidad Agropecuaria y Rural, Santiago, Chile. Recuperado de http://www.proterritorios.net/sites/ documentos/biblioteca/DI16.pdf

Echeverri, R. y Ribero, M. P. (2002).Nueva ruralidad. Visión del territorio en América Latina y el Caribe, San José, Costa Rica: IICA.

Echeverri, R., Rodríguez, A. y Sepúlveda, S. (2003).Competitividad territorial. Elementos para la discusión, 7, IICA. Recuperado de http:// legacy.iica.int/Esp/organizacion/LT GC/DesRural/ Publicaciones\%20Desarrollo\%20Rural/Sin07_2003.pdf

Gómez, S. (2002).La “Nueva ruralidad” ¿Qué tan nueva? Santiago, Chile: LOM Ediciones.

Grajales, S. y Concheiro, L. (2009). Nueva ruralidad y desarrollo territorial. Una perspectiva desde los sujetos sociales.Veredas Revista del Pensamiento Sociológico, 10 (18), 145-167. Recuperado de http:// r1.ufrrj.br/geac/portal/wp-content/uploads/2012/10/CONCHEIRONuevadesarrolloderritorial.pdf

IICA (2000).Nueva ruralidad: el desarrollo rural sustentable en el marco de una nueva lectura de la ruralidad, San José, Costa Rica: Instituto Interamericano de Cooperación para la Agricultura (IICA).

Kay, C. (2009). Estudios rurales en América Latina en el periodo de globalización neoliberal: ¿Una nueva ruralidad?Revista Mexicana de 
Polis, Revista Latinoamericana, $N^{o} 47,2017$

Sociología.71(4), 607-645. Recuperado de http://www.redalyc.org/ articulo.oa?id=32113274001

Llanos-Hernández, L. (2010). El concepto de territorio y la investigación en ciencias sociales.Agricultura, Sociedad y Desarrollo. 7 (3), 207-220. Recuperado de http://www.redalyc.org/articulo.oa?id=360533086001

López, J., Castañeda, T. y González, J. (2016). Innovation and Networks Collaboration in theCompetitiveness of a LocalizedAgri-foodSystem (LAS) of Artisan Bread.International Review of Management and Business Research. 5 (2), 462-472. Recuperado de http:// www.irmbrjournal.com/papers/1465538066.pdf

López, J. (2011).Acción Colectiva: El Caso de la Concentración de Panaderías Artesanales de Tecomatlán. Trabajo Terminal de Maestría en Agroindustria Rural, Desarrollo Territorial y Turismo Agroalimentario, Universidad Autónoma del Estado de México.

Mattes, J. (2012). Dimensions of Proximity and Knowledge Bases: Innovation between Spatial and Non-spatial Factors. Regional Studies. 46 (8), 1085-1099.doi:10.1080/00343404.2011.552493

Muchnik, J. (2012). Sistemas agroalimentarios localizados: desarrollo conceptual y diversidad de situaciones. En G. Torres, y R. M. Larroa (Coord.). Sistemas Agroalimentarios Localizados, Identidad Territorial, Construcción de Capital Social e Instituciones. (pp. 25-42). México, UNAM.

Pérez, E. (2004). El mundo rural latinoamericano y la nueva ruralidad.Nómadas,(20) 180-193. Recuperado de http:// www.redalyc.org/pdf/1051/105117734017.pdf

Pérez, E. y Farah, M. A. (2002). Los modelos de desarrollo y las funciones del medio rural en Colombia.Cuadernos de Desarrollo Rural,(49) 928. Recuperado de http://www.redalyc.org/articulo.oa?id=11704902

Riffo, L. (2013). 50 años del ILPES: evolución de los marcos conceptuales sobre desarrollo territorial.CEPAL Serie Desarrollo Territorial. (15), Recuperado de http://repositorio.cepal.org/bitstream/handle/11362/ 7248/1/S1303593_es.pdf

Rodríguez, G. y Rangel, C. (2005). Estudio del sistema agroalimentario localizado, SIAL, de la concentración de fábricas de bocadillo de guayaba en las provincias de Vélez y Ricaurte en Colombia.Bogotá, Colombia: Corporación Colombiana de Investigación Agropecuaria. Recuperado de http://www.corpoica.org.co/

Sandoval, N. V. (2003).Implementación de la Metodología de Sistemas Agroalimentarios Localizados (SIAL) en la cadena agroindustrial 
del Almidón agrio de Yuca en el norte del Departamento del Cauca. (Tesis pregrado), Universidad Nacional de Colombia, Palmira Valle, Colombia.Recuperado de http://library.ciat.cgiar.org/

Schejtman, A. y Berdegué, J. (2004). Desarrollo Territorial Rural.Debates y temas rurales No. 1. RIMISP, Centro Latinoamericano para el Desarrollo Rural. Recuperado de http://www.rimisp.org/wp-content/ files_mf/1363093392schejtman_y_berdegue2004_desarrollo_ territorial_rural_5_rimisp_CArdumen.pdf

Torre, A. y Rallet, A. (2005). Proximity and Localization.Regional Studies. 39 (1) 47-59.doi: 10.1080/003434005200032084

Torre, A. (2014). Proximity relations at the heart of territorial development processes. EnA. Torre y F. Wallet (Eds), Regional development and proximity relations, New Horizons in regional Science, Edward Elgar, London, 375p.

Tremblay, D. G., Klein, J. L., Fontan, J. M. y Rousseau, S. (2004). Territorial proximity and innovation: a Survey of Montreal Region.Research Note, Núm. 2004-06A, Télé-Université du Québec, Montreal, pp. 1-18.Recuperado de https://www.teluq.uquebec.ca/chaireecosavoir/ pdf/NRC04-06A.pdf

Recibido: 05.10.15

Aceptado: 27.08.16 